\title{
Development of Application-Based Badminton Learning Model at Faculty of Sports Science Medan State University
}

\author{
Usman Nasution ${ }^{1, *}$ Ibrahim $^{2}$, Zulpikar Ilham ${ }^{3 .}$ \\ ${ }^{1,2,3}$ Department of Physical Education Healt and Recreation of Faculty Of Sport Science Universitas Negeri Medan, \\ Jl. Willem Iskandar Pasar V Medan Estate \\ *Corresponding author. Email: $\underline{\text { usman@ } @ \text { unimed.ac.id }}$
}

\begin{abstract}
This research is a development research that aims to improve learning outcomes, develop android-based application media and as a source/learning material that can be used for the continuation of future lectures as well as assisting in the field of sports science, especially in badminton. Development research is the development of learning media in the form of applications that are developed to help improve competence in lecturing badminton games during the COVID19 pandemic The media developed in the form of learning applications that are used as teaching materials in online and face-to-face learning. The learning application contains lecture materials in each face-to-face amount in the form of lecture descriptions, learning variations videos, quizzes, and other instructions that support the online learning process. The research method used is a quantitative approach and uses the Research \& Development (R \& D) method from Sugiono by developing products, testing the effectiveness of products that achieve the desired goals. The research sample is the fifth semester students who take the badminton game course in the Physical Education, Health and Recreation Study Program, FIK UNIMED.
\end{abstract}

Keywords: Application-Based, badminton, learning model.

\section{INTRODUCTION}

Learning and teaching sports has always been close to physical activity. One of the physical activities that students usually do is movement to learn to master a skill. Skills learning is carried out through three stages of sports learning, namely: (1) cognitive stage, (2) association stage, (3) automation stage. At the cognitive stage, the teacher provides material understanding to students about the new movement in what and how it is done. The association stage is carried out after students answer cognitive questions and effectively organize movement patterns to produce movement by constructing abilities and attitudes, consistency and confidence. [1]

Development research is a reflection of the desire to know something in the form of facts or natural phenomena, with attention or initial observations of facts or phenomena is the beginning of a research desire that raises a question or problem which is basically a systematic research with the aim of gaining knowledge. useful for answering questions or solving in everyday life. Learning products with the development of information media must be carried out in stages, comprehensively and comprehensively with the aim of increasing student competence or learning outcomes.

Badminton is a sport favored by the Indonesian people, and badminton is also one of the materials taught in physical education in Indonesia. Recently, the rapid development of broadband connections has provided many opportunities to access quality online materials. One of the most important factors in the learning process is to plan sessions with a focus on the variability of practice, regarding the needs of the trainees. In the field of badminton training for physical education students this trend is also developing. The effective efficacy of mixed learning as a way of teaching and learning has attracted the attention of many teachers, administrators and researchers in physical education. In addition to the potential benefits, this new learning pattern also creates challenges such as digital media in space, access to learning tools, teaching 
methods, and learning styles that physical education research is trying to overcome.

Nutaracot (2019) in his research said that learning using application media based on motion analysis and the correct number of stroke treatments helped badminton players in evaluating the correct results and the number of movements in a match. So in this study, researchers are interested in designing an Android-based learning application that can be accessed by students to facilitate the process of lecturing the badminton game. [2]

Applications that are designed to describe all lecture activities in each face-to-face that present:

- A collection of basic technical videos

- A collection of learning variation videos that are adjusted gradually based on ability

The use of multimedia in the process of learning and practicing badminton is also very helpful in the learning and training process. In addition to seeing the correctness of motion, the role of multimedia can also help to determine the speed of the shuttlecock during the match. [3].

This research is designed for online lectures, where face-to-face lectures cannot be carried out due to the COVID-19 pandemic. In a study conducted, online learning in badminton lectures showed positive and satisfying student perceptions where the material presented facilitates students in achieving the expected competencies [4].

\section{METHOD}

In this study, the authors use research methods R \& D by looking at the results of student learning effectiveness. The number of samples as many as 30 people, who came from students aged 17 to 19 years.

The data collection used in this study is by using a skill test of the basic techniques of badminton. the results of the data are then presented to see the improvement that occurred after this product was tested on a small and large scale.

\section{RESULT}

In this study, the data analysis used is to test the effectiveness of the learning application media that has been designed. The data presented below are the results of learning from some basic techniques in the badminton game which were collected as instruments. The data analysis used was a t-test of the basic techniques of playing badminton. The results of data analysis can be seen in the table below.

Table 1. Learning outcomes badminton game skills

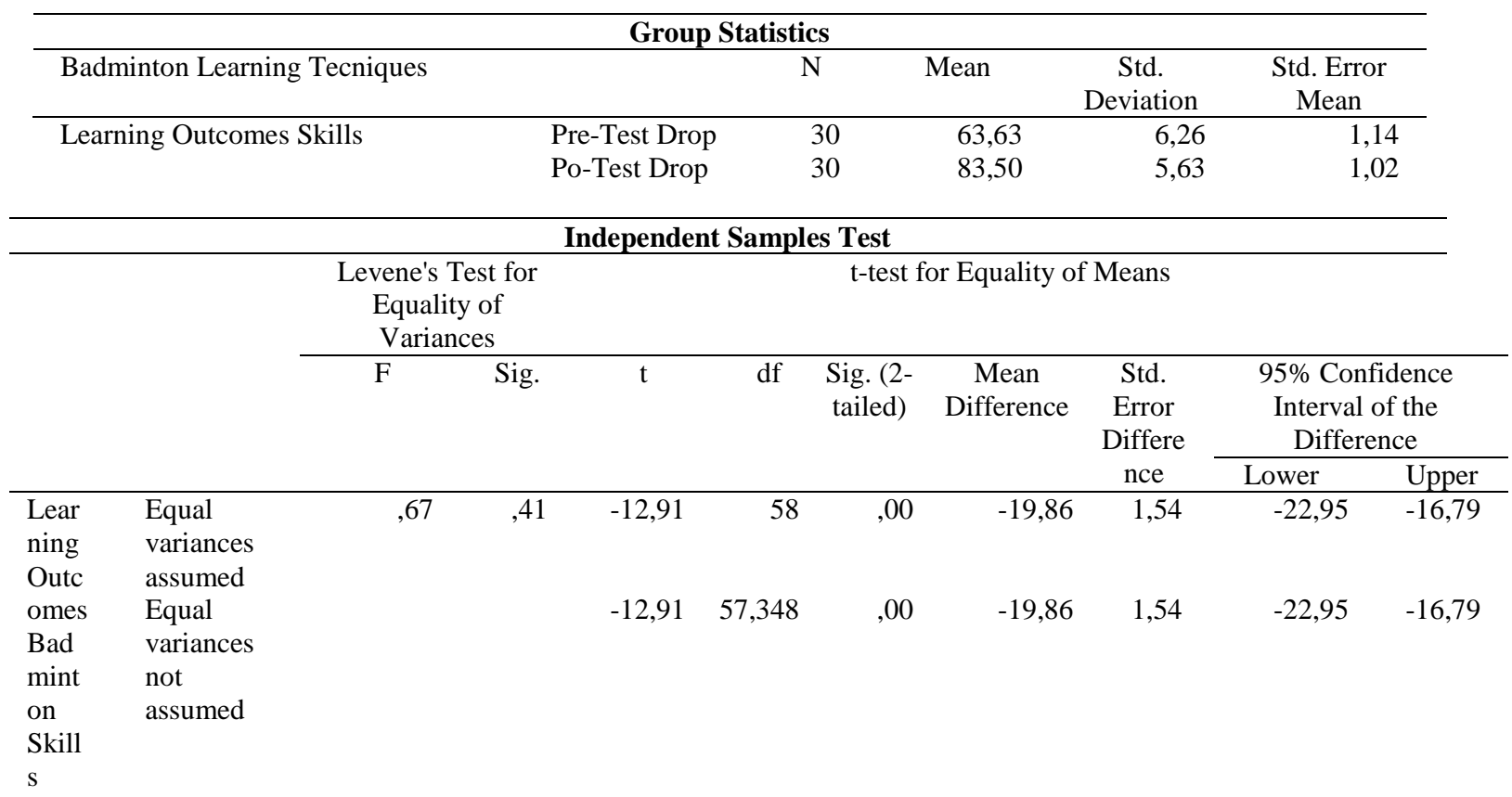


Based on the overall results of the t-test on learning the basic techniques of playing badminton, the results of the pre-tet and po-test scores have a significant value. Because all basic badminton learning techniques starting from serve, lob, drop and smash have a Sig. (2-tailed) value of $0.000<0.05$, then there is a significant difference between the results of the pre-test and po-test scores in technical learning. basic badminton game.

\section{CONCLUSION}

This research development process is expected to be an alternative learning in badminton lectures. From the results of the data analysis above, it can be concluded that of the four basic techniques of badminton games, namely serve, lob, drop and smash have a significant increase in technical results, so it can be concluded that through the badminton game learning application media which is designed to suit student learning needs, it has a positive impact on students' learning needs. learning is carried out both in groups, independently and done online

\section{REFERENCES}

[1] Sadri, K., Mohammadzadeh, H., Khani, M. The Effect of Contextual Interference on Acquisition and Learning Badminton Skills among Children aged from 10 to 12. Jakarta : Citra Rineka, 2018. DOI:

https://iranjournals.nlai.ir/handle/123456789/67097 1

[2] Huy, C,V., Luong, N.T., Vu, N,N. "Blended Learning In Badminton Training For Professionals: Students' Perceptions And Performance Impacts" (European Journal of Physical Education and Sport Science) chapter 6 pp 28-35, 2020. DOI: 10.46827/EJPE.V6I6.3226

[3] Chu, L.1. \& Chen, W.c. Multimedia Application to Motor Skill Learning. In J. Bourdeau \& R. Heller (Eds.), Proceedings of ED-MEDIA 2000--World Conference on Educational Multimedia, Hypermedia \& Telecommunications Montreal, (Canada: Association for the Advancement of Computing in Education (AACE)). pp. 1292-1293, 2000 .

[4] Nutracot. "Model for Practice Badminton Basic Skills by using Motion Posture Detection from Video Posture Embedding and One-Shot Learning Technique" (Proceedings of the 2019 2nd Artificial Intelligence and Cloud Computing Conference. pp 117-124, 2019. DOI: 10.1145/3375959.3375981 